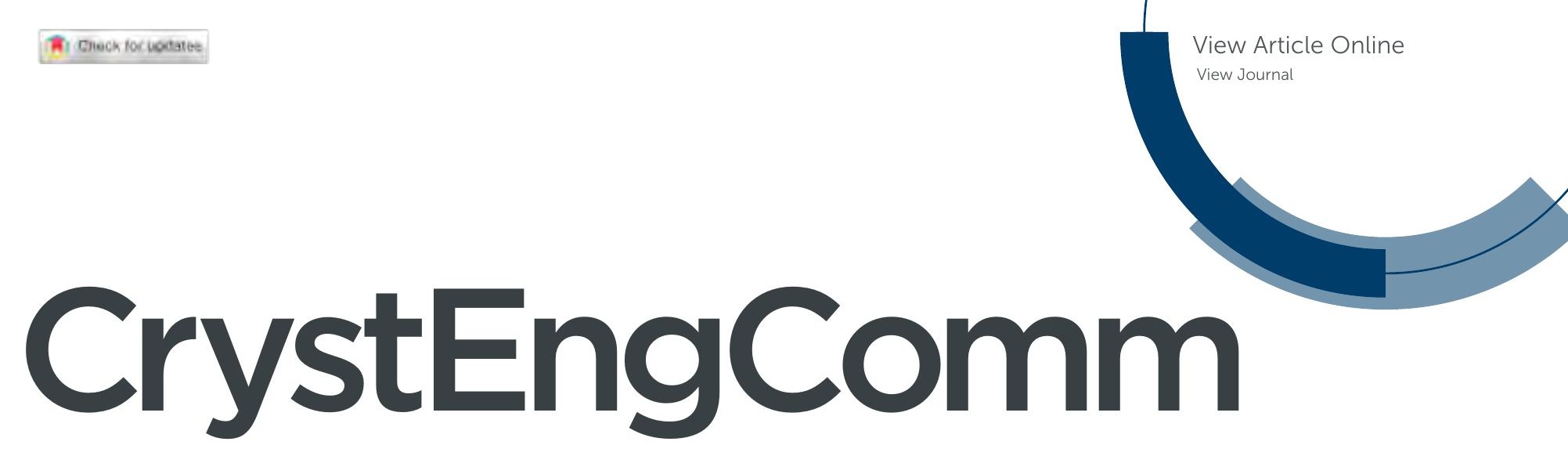

Accepted Manuscript

This article can be cited before page numbers have been issued, to do this please use: S. Uriel Rubio, L.

González, S. Graus, R. M. Tejedor, A. Chantapally and J. L. Serrano, CrystEngComm, 2020, DOI:
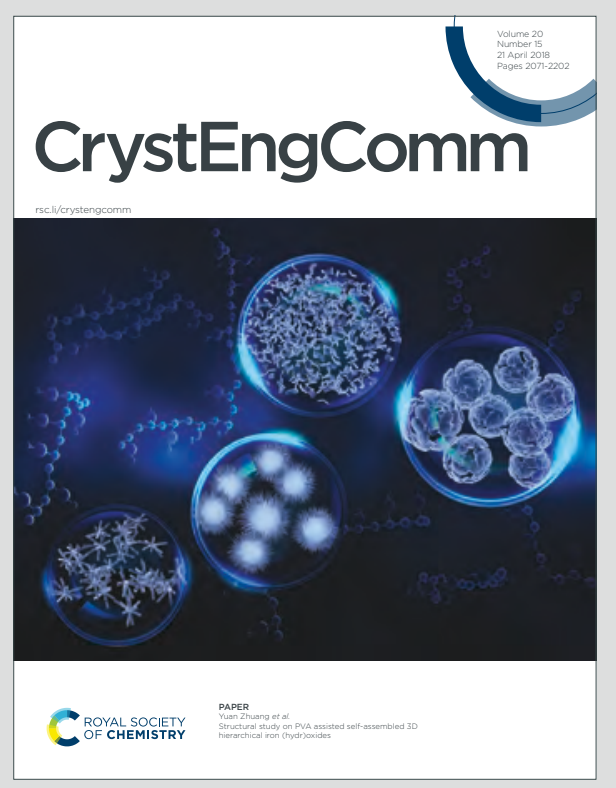

This is an Accepted Manuscript, which has been through the Royal Society of Chemistry peer review process and has been accepted for publication.

Accepted Manuscripts are published online shortly after acceptance, before technical editing, formatting and proof reading. Using this free service, authors can make their results available to the community, in citable form, before we publish the edited article. We will replace this Accepted Manuscript with the edited and formatted Advance Article as soon as it is available.

You can find more information about Accepted Manuscripts in the Information for Authors.

Please note that technical editing may introduce minor changes to the text and/or graphics, which may alter content. The journal's standard Terms \& Conditions and the Ethical guidelines still apply. In no event shall the Royal Society of Chemistry be held responsible for any errors or omissions in this Accepted Manuscript or any consequences arising from the use of any information it contains. 


\title{
ARTICLE
}

\section{The combination of halogen and hydrogen bonding: a versatile tool in coordination chemistry}

Received 00th January 20xx,

Accepted 00th January 20xx

DOI: $10.1039 / \times 0 \times x 00000 x$

www.rsc.org/

\author{
Lucia González, ${ }^{a}$ Sara Graus, ${ }^{a}$ Rosa M. Tejedor,, ,a Anjana Chanthapally, ${ }^{c}$ José Luis Serrano a and \\ Santiago Uriel*a
}

\begin{abstract}
4-lodo-N-(4-pyridyl)benzamide (INPBA) and four derived coordination complexes were synthesized in order to explore the combination of halogen and hydrogen bonding interactions in coordination chemistry. The electron-withdrawing carbonyl group attached to the aromatic ring bearing the iodine atom has been introduced to increases its halogen bonding ability. Single crystal X-ray diffraction analyses of INPBA, $\left[\mathrm{Ag}\left(\right.\right.$ INPBA $\left._{2}\right] \mathrm{NO}_{3}(\mathbf{1}),\left[\mathrm{ZnBr}_{2}\left(\right.\right.$ INPBA $\left._{2}\right](\mathbf{2}),\left[\mathrm{Zn}(\mathrm{OCOPh})_{2}(\text { INPBA })_{2}\right](3)$ and $\left[\mathrm{Hgl}_{2}(\text { INPBA })\right]_{n}(4)$ show the versatility of the INPBA building block yielding a variety of interesting different structures. lodine atom arrangement plays a key role by reinforcing and extending the crystalline structures into diverse 3D supramolecular networks via $|\cdots \mathrm{O},| \cdots \mathrm{N}$, and $|\cdots|$ halogen bonding interactions. Besides of this, the overall supramolecular architecture of the coordination complexes is modulated by the $\mathrm{N}-\mathrm{H} \cdots \mathrm{O}, \mathrm{N}-\mathrm{H} \cdots \mathrm{Br}$, and $\mathrm{C}-\mathrm{H} \cdots \mathrm{O}$ hydrogen bonds formed by the carboxamide group. The combination of both, halogen and hydrogen bonds, allow to design very different coordination networks.
\end{abstract}

\section{Introduction}

The physical and chemical properties of molecular materials in the solid state are controlled by the arrangement of the molecular building blocks. The adequate design of these supramolecular organizations afford control over the properties of these materials. ${ }^{1-4}$ One of the most powerful strategies to control the solid-state structure of metal-containing compounds is the assembly of metallo-tectons through non-covalent interactions. Therefore, the organic ligand characteristic such as rigidity, flexibility, binding and its potential interaction sites $^{5}$ can largely determine the supramolecular organization. In the solid state the non-covalent interactions such as hydrogen bonding, ${ }^{6,7} \pi-\pi$ stacking, ${ }^{8} \mathrm{CH} \cdots \pi$ interaction, ${ }^{8}$ and, the most recent and therefore least explored, halogen bonding interactions ${ }^{9-13}$ direct the structure of the molecular materials. Moreover, synergy between non-covalent interactions can determine the supramolecular assembly. ${ }^{14}$ To study the ability to direct the structure of the combination of hydrogen and halogen bonds in coordination chemistry, we have prepared 4-iodo-N-(4-pyridyl)benzamide (INPBA) (Chart 1) and four metal complexes of this ligand with metal ions $\mathrm{Ag}^{+}, \mathrm{Zn}^{2+}$ and $\mathrm{Hg}^{2+}$, which give rise to complexes with a low coordination number. The cooperation between the halogen bonding interactions and other non-covalent interactions has been

a. Departamento de Química Orgánica, Instituto de Nanociencia de Aragón (INA)-Instituto de Ciencia de Materiales de Aragón (ICMA), Universidad de Zaragoza-CSIC, Zaragoza (Spain)

b. Centro Universitario de la Defensa, Academia General Militar, 50090 Zaragoza, Spain

Department Chemistry, National University of Singapore,43, Singapore

† Footnotes relating to the title and/or authors should appear here.

Electronic Supplementary Information (ESI) available: X-ray crystallographic files (CIF)CCDC 1423795-1423799 contain the supplementary crystallographic data for previously studied ${ }^{15-20}$ to develop metal-free liquid crystals, ${ }^{21}$ two-dimensional structures ${ }^{22}$ and porous materials. ${ }^{23}$

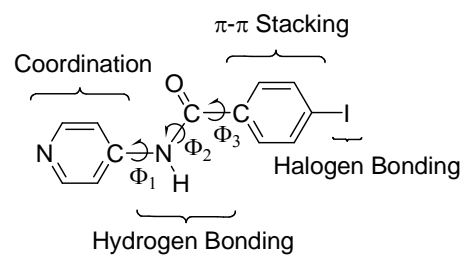

Chart 1: 4-lodo-N-(4-pyridyl)benzamide (INPBA)

INPBA has three active functional groups (Chart 1 ) : iodine, pyridine and carboxamide. The iodo-substituent is partially activated ${ }^{24,25}$ by the electron-withdrawing carbonyl of amide group attached to the aromatic ring ${ }^{26}$ and is able to take part in $\mathrm{C}-\mathrm{I} \cdots$ oxygen, $\mathrm{C}-\mathrm{|} \cdots$ nitrogen, $\mathrm{C}-\mathrm{|} \cdots \pi, \mathrm{C}-\mathrm{|} \cdots \mid-\mathrm{C}$ and $\mathrm{C}-\mathrm{|} \cdots \mathrm{X}-\mathrm{M}$ halogen bondings. ${ }^{27-30}$ As in previous works, the halogen bonding is expected to generate different supramolecular architectures, including helical chains. ${ }^{31-37}$ Furthermore, INPBA contains a carboxamide group that plays an important role in the supramolecular organizations through its participation in both hydrogen and halogen bonds

Taking into account this previous experience we have designed in this paper three new coordination complexes namely
$\left[\mathrm{Ag}(\mathrm{INPBA})_{2}\right]_{\mathrm{NO}_{3}}$
(1),
[ $\left.\mathrm{ZnBr}_{2}(\text { INPBA })_{2}\right]$

$\left[\mathrm{Zn}(\mathrm{OCOPh})_{2}(\mathrm{INPBA})_{2}\right](3)$, and one extended coordination polymer, $\left[\mathbf{H g l}_{\mathbf{2}}(\text { INPBA) }]_{\mathbf{n}}\right.$ (4). The synthesis and the crystal structure of INPBA and metal complexes are described. The different supramolecular structures obtained in the solid state have been analysed in base of non-covalent interactions observed by the Hirshfeld surface calculations. Also, the ability of INPBA as a halogen bonding donor is evaluated by theoretical calculations. 


\section{ARTICLE}

Table 1. Crystallographic data for INPBA, $\left[\mathrm{Ag}(\text { INPBA })_{2}\right] \mathrm{NO}_{3}(1),\left[\mathrm{ZnBr}_{2}(\mathrm{INPBA})_{2}\right](2),\left[\mathrm{Zn}(\mathrm{OCOPh})_{2}(\mathrm{INPBA})_{2}\right](3)$ and $\left[\mathrm{HgI}_{2}(\text { INPBA })\right]_{n}(4)$

\begin{tabular}{|c|c|c|c|c|c|}
\hline Compound & INPBA & 1 & $2^{(a)}$ & 3 & 4 \\
\hline Empirical formula & $\mathrm{C}_{12} \mathrm{H}_{9} \mathrm{IN} \mathrm{N}_{2} \mathrm{O}$ & $\mathrm{C}_{24} \mathrm{H}_{18} \mathrm{~N}_{5} \mathrm{O}_{5} \mathrm{I}_{2} \mathrm{Ag}$ & $\mathrm{C}_{24} \mathrm{H}_{18} \mathrm{~N}_{4} \mathrm{O}_{2} \mathrm{Br}_{2} \mathrm{l}_{2} \mathrm{Zn}$ & $\mathrm{C}_{38} \mathrm{H}_{28} \mathrm{I}_{2} \mathrm{~N}_{4} \mathrm{O}_{6} \mathrm{Zn}$ & $\mathrm{C}_{12} \mathrm{H}_{9} \mathrm{Hgl}_{3} \mathrm{~N}_{2} \mathrm{O}$ \\
\hline Formula weight & 324.11 & 818.10 & 873.41 & 955.81 & 778.50 \\
\hline Crystal System & Monoclinic & Triclinic & Monoclinic & Orthorhombic & Monoclinic \\
\hline a, $\AA$ & $5.3119(3)$ & $9.3872(5)$ & $9.7184(2)$ & $14.2615(6)$ & $4.303(12)$ \\
\hline $\mathrm{b}, \AA$ & $14.3087(6)$ & $11.4744(4)$ & $27.7576(6)$ & $8.9996(3)$ & $14.824(5)$ \\
\hline$c, \AA$ & $15.0594(9)$ & $13.2529(6)$ & $9.8707(2)$ & $29.6078(13)$ & $25.840(8)$ \\
\hline$\alpha, \operatorname{deg}$ & & $107.591(4)$ & & & \\
\hline$\beta$, deg & $90.017(5)$ & $110.075(5)$ & $91.040(2)$ & & \\
\hline$\gamma, \operatorname{deg}$ & & $94.437(4)$ & & & \\
\hline$V, \AA^{3}$ & $1144.61(11)$ & $1251.65(10)$ & $2662.27(10)$ & $3800.1(3)$ & $1648.3(9)$ \\
\hline $\mathrm{T}, \mathrm{K}$ & $248(2)$ & $292(2)$ & $100(2)$ & $100(2)$ & $293(2)$ \\
\hline Space group & $\mathrm{P}_{1} / \mathrm{c}$ & Pì & $\mathrm{P}_{1} / \mathrm{c}$ & Pbcn & $\mathrm{P}_{1} / \mathrm{c}$ \\
\hline z & 4 & 2 & 4 & 4 & 4 \\
\hline$\mu($ Mo K $\alpha), \mathrm{mm}^{-1}$ & 2.777 & 3.318 & 23.252 & 2.321 & 14.950 \\
\hline$\Theta$ range, deg & 1.96 to 28.32 & 1.75 to 26.37 & 3.18 to 74.29 & 2.68 to 26.37 & 3.15 to 25.00 \\
\hline Refl. collected & 8308 & 8687 & 20071 & 40876 & 5264 \\
\hline Uniq reflect/ Rint & $2604 / 0.0384$ & $5123 / 0.0239$ & $5330 / 0.0612$ & 3879 / 0.0326 & 2884 / 0.0340 \\
\hline $\mathrm{R} 1 / \mathrm{wR} 2(\mathrm{I}>2 \sigma)$ & $0.0376 / 0.0655$ & $0.0295 / 0.0638$ & $0.0500 / 0.1287$ & $0.0315 / 0.0726$ & $0.0420 / 0.0778$ \\
\hline R1/wR2 (all data) & $0.0529 / 0.0703$ & $0.0336 / 0.0677$ & $0.0521 / 0.1304$ & 0.0382 / 0.0764 & $0.0666 / 0.0872$ \\
\hline Max. shift/esd & 0.001 & 0.009 & 0.001 & 0.001 & 0.004 \\
\hline Residual $\rho / e \AA^{-3}$ & 0.669 and -0.633 & 1.181 and -0.975 & 1.895 and -2.123 & 2.016 and -1.927 & 1.161 and -1.361 \\
\hline
\end{tabular}

(a) $\mathrm{Cu}-\mathrm{K} \alpha$ radiation

\section{Results and discussion}

4-lodo-N-(4-pyridyl)benzamide (INPBA) was prepared by treating 4-iodobenzoyl chloride with 4-aminopyridine in the presence of triethylamine. INPBA crystallizes in the monoclinic $P 2_{1} / c$ space group, with one independent molecule in the asymmetric unit. The crystallographic data of INPBA and complexes from 1 to $\mathbf{4}$ are listed in Table 1. The bond distances and angles of INPBA were as expected. This ligand consists of three structural parts: a pyridyl unit, a central carboxamide group and a $p$-iodophenyl unit (Chart 1 ). These structural moieties form three regions with conformational degrees of freedom defined by the torsion angles $\Phi_{1} \quad\left(\Phi_{1}=\right.$ $\mathrm{C}(9)-\mathrm{C}(8)-\mathrm{N}(1)-\mathrm{C}(7)), \quad \Phi_{2}\left(\Phi_{2}=\mathrm{C}(8)-\mathrm{N}(1)-\mathrm{C}(7)-\mathrm{C}(4)\right)$ and $\Phi_{3}\left(\Phi_{3}=N(1)-C(7)-C(4)-C(3)\right)$, which allow it to fit the local environment (Figure 1 and S1 in the ESI). The INPBA central $\mathrm{C}-\mathrm{C}-\mathrm{N}-\mathrm{C}$ spacer unit is almost planar, as shown by the torsion angle $\left(\Phi_{2}=-177 \cdot 3^{\circ}\right)$. However, the aromatic rings are markedly twisted out of this plane $\left(\Phi_{1}=33.7^{\circ}\right.$ and $\Phi_{3}=28.4^{\circ}$ ) (Table 2). This conformation is similar to that of $\mathrm{N}$-(4-pyridyl)benzamide ${ }^{38}$ (NPBA) $\left(\Phi_{1}=-16.8^{\circ}, \Phi_{2}=178.4^{\circ}\right.$ and $\left.\Phi_{3}=-34.3^{\circ}\right)$ and 4-fluoro-N-(pyridin-4-yl)benzamide ${ }^{39}$ (FNPBA) $\left(\Phi_{1}=17.6^{\circ}, \Phi_{2}=\right.$ $-177.8^{\circ}$ and $\Phi_{3}=35.4^{\circ}$ ) (Figure S2, ESI).

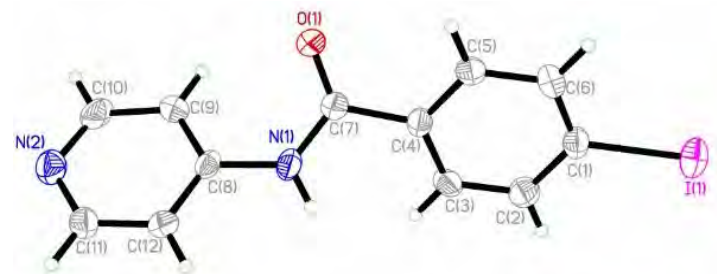

Figure 1. ORTEP showing thermal ellipsoids at the $50 \%$ probability level and numbering scheme for the INPBA crystal structure.

The INPBA optimized torsional angles $\Phi_{2}$ and $\Phi_{3}$ (B3LYP-D3/6$311 \mathrm{G}^{++}(d, p)$ and DGDZVP, see Experimental Section) are, respectively, $-179^{\circ}$ and $25.8^{\circ}$, similar to the experimental conformation. However, the calculated angle $\Phi_{1}$ is $1.2^{\circ}$, indicating a planar arrangement of the pyridyl and amide groups. The electrostatic potential on the 0.002 electron/A molecular surface of optimized INPBA (Figure 2) exhibits the characteristic positive electrostatic potential at the end region of the iodine atom along the $\mathrm{C}-\mathrm{I}$ bond that corresponds to the $\sigma$-hole. The maximum value for the relative electrostatic potential on the iodine atom is $33.7 \mathrm{kcal} / \mathrm{mol}$ for INPBA. This value is intermediate between the electrostatic potential 
calculated for weak halogen-bonding donors such as 2,8-diiodo-6H,12H-5,11-methanodibenzodiazocine $\mathrm{kcal} / \mathrm{mol})^{40}$ and the powerful halogen bond donor 1,4-bis(iodoethynyl)benzene $(46.2 \mathrm{kcal} / \mathrm{mol}) .{ }^{21}$

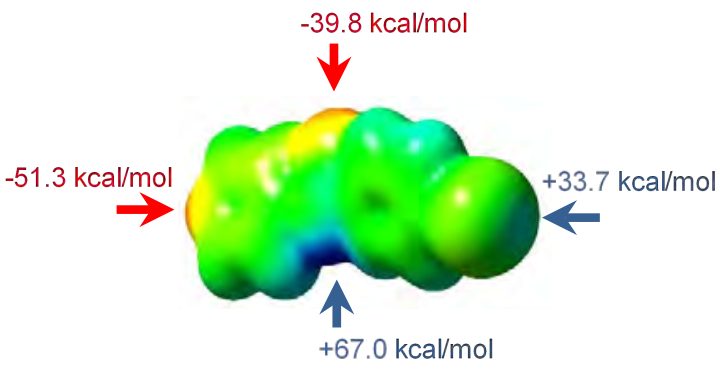

Figure 2. Computed electrostatic potential of the optimized INPBA obtained by molecular electron density 0.002 electron/Å. Electrostatic values range from -51.4 (red) to 67.1 (blue) $\mathrm{kcal} / \mathrm{mol}$.

The lower ESP value for the iodine atom of $\mathrm{N}$-(4-iodophenyl)isonicotinamide $(27.0 \mathrm{kcal} / \mathrm{mol})$ (Figure $\mathrm{S} 3$, ESI) compared with $33.7 \mathrm{kcal} / \mathrm{mol}$ for INPBA proves the effect on binding of the electron-withdrawing carbonyl to halogenated aromatic ring and this suggests that INPBA has a stronger halogen-bonding ability. The hydrogen atom of the INPBA amide group also shows high positive electrostatic potential. As expected, two minima of electrostatic potential are sited on the pyridine nitrogen atom and on the oxygen atom of the amide group. These results designate that INPBA can act as a halogen bonding donor or acceptor and hydrogen bonding acceptor or donor as evidenced by its crystalline structure described below.

Table 2. Torsional angles of N-(4-pyridyl)benzamide (NPBA), 4-fluoro-N-(pyridin-4-yl)benzamide (FNPBA), INPBA and INPBA in $\mathbf{1}$ to $\mathbf{4}$ (Torsional angles, $\Phi_{1} \Phi_{2} \Phi_{3}$, in Figure 2)

\begin{tabular}{|c|c|c|c|c|}
\hline & Conform. & $\Phi_{1}$ & $\Phi_{2}$ & $\Phi_{3}$ \\
\hline $\mathrm{NPBA}^{38}$ & - & -16.8 & -178.4 & -34.3 \\
\hline FNPBA $^{39}$ & & 17.6 & -177.8 & 35.4 \\
\hline INPBA & - & 33.7 & -177.3 & 28.4 \\
\hline \multirow[t]{2}{*}{1} & \multirow{2}{*}{ cis } & -6.0 & 174.5 & 4.3 \\
\hline & & 16.6 & -179.8 & 14.9 \\
\hline \multirow[t]{2}{*}{2} & \multirow{2}{*}{ trans } & 4.5 & 171.5 & 35.7 \\
\hline & & -18.4 & -172.8 & -26.8 \\
\hline 3 & trans & -4.4 & 172.1 & -21.9 \\
\hline 4 & - & 21.0 & 176.1 & 32.0 \\
\hline
\end{tabular}

The supramolecular arrangement of INPBA in crystal structure shows chains of molecules, along the $b$ axis, aligned head-to-tail by halogen bonding $C(1)-I(1) \cdots N(2)\left(2.989 \AA\right.$ A $\left.175.3^{\circ}\right)$ (Table 3).
Table 3. Distances and angles of halogen bonds in INPBA and crystaV/struettires 1 totone 4

\begin{tabular}{|c|c|c|c|c|}
\hline & $C-1 \cdots A$ & $C-\mid \cdots A(\AA)$ & $C-I(\AA ̊)$ & $<(C-\mid \cdots A)($ deg $)$ \\
\hline INPBA & $C(1)-I(1) \cdots N(2)^{i}$ & $2.989(3)$ & $2.111(4)$ & $175.3(1)$ \\
\hline 1 & $C(22)-I(2) \cdots O(5)^{i i}$ & $3.498(4)$ & $2.104(4)$ & $152.5(1)$ \\
\hline 2 & $C(22)-I(2) \cdots \mid(1)^{i i i}$ & $3.938(1)$ & $2.092(6)$ & $166.2(2)$ \\
\hline 3 & $C(1)-I(1) \cdots O(1)^{\mathrm{iv}}$ & $3.257(2)$ & $2.098(3)$ & $148.8(1)$ \\
\hline 4 & $C(1)-I(1) \cdots \mid(3)^{v}$ & $3.858(1)$ & $2.10(1)$ & $175.5(3)$ \\
\hline
\end{tabular}

(v) $1+x, 1.5-y,-1 / 2+z$.

The $\mathrm{C}-\mid \cdots \mathrm{N}$ interaction distance (green in Figure 3 ) corresponds to a reduction of approximately $15 \%$ of the sum of the van der Waals radii of $\mathrm{N}$ and I ( $3.53 \AA$ ). The chains of INPBA are joined by hydrogen bonds (in blue in Figure $3 a$ ) between carboxamide groups, thus resulting in layers in the $a b$ plane that pack in an anti-parallel fashion to afford a centric crystal. Hydrogen bonds distances and angles are gathered in Table S1 in the ESI. These layers are practically isolated from each other due to the twisted conformation of the phenyl moieties prevents the $\pi-\pi$ stacking interactions (Figure $3(b)$ ).

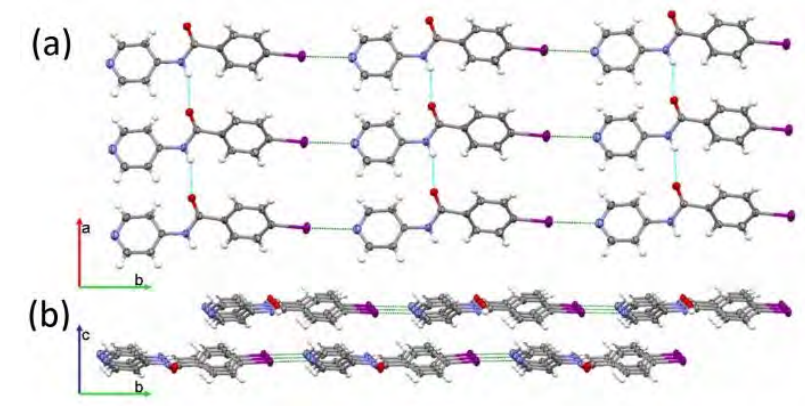

Figure 3. INPBA structure (a) $2 \mathrm{D}$ sheets formed by $\mathrm{N}_{\text {pyr }} \cdots$ / halogen bonding in green and perpendicular $\mathrm{N}-\mathrm{H} \cdots \mathrm{O}=\mathrm{C}$ carboxamide hydrogen bond in blue; (b) Isolated layers. Thermal ellipsoids are drawn at the $50 \%$ probability level.

The dimers XB-exp and HB-exp extracted of the crystalline structure (Figure S4 in the ESI) were optimized with B3LYP-D3 using DGDZVP for iodine atom and $6-311 \mathrm{G}^{++}(d, p)$ for the rest of the atoms. The optimized dimers were designed as HB-opt and $\mathrm{XB}$-opt (Figure S4 in the ESI). The interaction energies and the key geometric parameters of the optimized dimers are gathered Table S2 in the ESI. The $\mathrm{C}-\mathrm{I} \cdots \mathrm{N}$ contact of the optimized dimers exhibits structural parameters close to experimental data. The negative interaction energy $(-6.6 \mathrm{kcal} / \mathrm{mol})$ proves the noncovalent interaction between the $\sigma$-hole of the iodine atom and the nitrogen atom of the pyridyl group. The dimer based on hydrogen bond converged to HB-opt that exhibit a $\mathrm{H} \cdots \mathrm{O}$ distance considerably shorter than the sum of the van der Waals radii and the experimental distance. The calculated interaction energy of HB-opt was $-16.6 \mathrm{kcal} / \mathrm{mol}$. The interaction energies and the geometric parameters of the optimized dimers confirm that both hydrogen and halogen bonds collaborate to support the crystalline structure INPBA. 


\section{Solid network of metal complexes}

The reaction of INPBA with $\mathrm{AgNO}_{3}, \mathrm{ZnBr}_{2}$ and $\mathrm{Zn}\left(\mathrm{NO}_{3}\right)_{2}$, in the presence of sodium benzoate, produced three discrete metal complexes, namely $\left[\mathrm{Ag}(\mathrm{INPBA})_{2}\right] \mathrm{NO}_{3}$ (1), $\left[\mathrm{ZnBr}_{2}(\text { INPBA })_{2}\right]$ (2), [Zn(OCOPh $\left.)_{2}(\text { INPBA })_{2}\right]$ (3). The reaction with $\mathrm{Hgl}_{2}$ yielded the extended coordination polymer $\left[\mathrm{HgI}_{\mathbf{2}}(\text { INPBA) }]_{\mathbf{n}}(\mathbf{4})\right.$. The solid state network of the complexes depends on the coordination number and the geometry of the metal ions and it is determined by the concomitant (or not) formation of hydrogen and halogen bonding and $\pi-\pi$ stacking interactions.

Silver complex $\left[\mathrm{Ag}(\mathrm{INPBA})_{2}\right] \mathrm{NO}_{3}$ (1). The crystal structure of 1 was solved in the $P-1$ triclinic space group and its asymmetric unit contains two INPBA ligands coordinated in a linear fashion to a silver atom and a nitrate anion. The pyridine rings of these two ligands form an angle of $36.5^{\circ}$ and the carbonyl groups $\mathrm{C}=\mathrm{O}(1)$ and $\mathrm{C}=\mathrm{O}(2)$ in Figure $4 \mathrm{a}$ are on the same side (cis conformation). This arrangement allows the formation of dimers by hydrogen bonding $(\mathrm{C}(5)-\mathrm{H} \cdots \mathrm{O}(1)$ $2.594 \AA, 172.6^{\circ} ; \mathrm{C}(11)-\mathrm{H} \cdots \mathrm{O}(2) 2.719 \AA, 143.2^{\circ}$ and $\mathrm{C}(20)-\mathrm{H} \cdots \mid(1)$ $3.336 \AA, 152.0^{\circ}$ ) as shown in Figure 4 a. These dimers are bound by hydrogen bonds that involve the iodine atom and these bonds give rise to ribbons $\left(C(9)-H \cdots I(1) 3.3421 \AA, 139.1^{\circ}\right)$, as shown in Figure $4 b$. The edge-to-edge hydrogen-bonding interactions $\left(\mathrm{C}_{\mathrm{Ar}}-\mathrm{H} \cdots \mid\right.$ ) promote a planar arrangement, in a similar way to the 1,4 and 1,3-bis(iodoethynyl)benzene derivatives. ${ }^{22}$

(a)
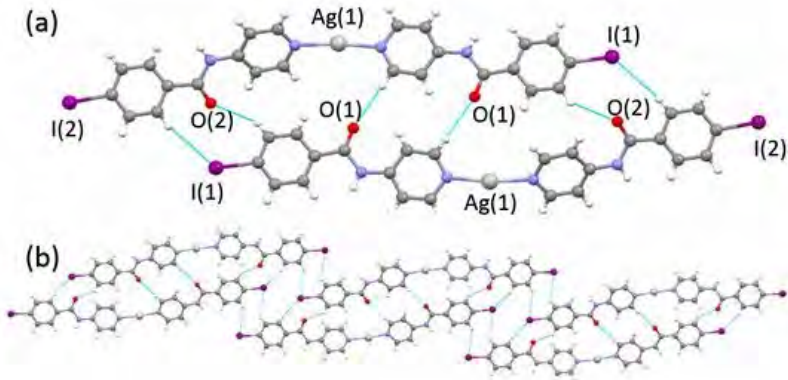

Figure 4. (a) A view showing $\mathrm{Ag}(\mathrm{I})$ coordination in 1 and hydrogen bonded dimer and (b) ribbons formed by edge-to-edge hydrogen-bonding interactions $\left(\mathrm{C}_{\mathrm{Ar}}-\mathrm{H} \cdots \mathrm{I}\right)$

The equatorial region of the iodine atoms with negative electrostatic potential bonds the metallic cation (in violet in Figure 5a). These results are consistent with the charge polarization model at the heavy halogen. ${ }^{27}$ The $\mathrm{C}-\mathrm{I} \cdots \mathrm{Ag}$ distances $(3.472,3.585 \AA$ ) are significantly shorter than the van der Waals contact, $3.70 \AA$ (van der Waals radius for $\mathrm{Ag}=1.72$ and $I=1.98 \AA$ ) and the $C-I \cdots A g$ angles are close to $90^{\circ}(97.9$ and $\left.108.6^{\circ}\right)$. These interactions link up the ribbons described above forming planes (Figure 5a).

Finally, the nitrate anions connect the planes by hydrogen bonds $\left(\mathrm{N}(2)-\mathrm{H} \cdots \mathrm{O}(5) 3.024 \AA\right.$, $158.8^{\circ}$ and $\mathrm{N}(4)-\mathrm{H} \cdots \mathrm{O}(4) 2.958$ $\left.\AA, 161.3^{\circ}\right)$, an $\mathrm{Ag} \cdots \mathrm{O}$ bifurcated interaction $(\mathrm{Ag}(1) \cdots \mathrm{O}(3) 2.856$ $\AA ̊ \mathrm{Ag}(1) \cdots \mathrm{O}(4) 2.934 \AA$ ) and halogen bonding $\mathrm{C}-\mathrm{I}(2) \cdots \mathrm{O}(5)$ $\left(3.498 \AA, 152.5^{\circ}\right)$, which gives rise to a three-dimensional network (Figure $5 b$ ).
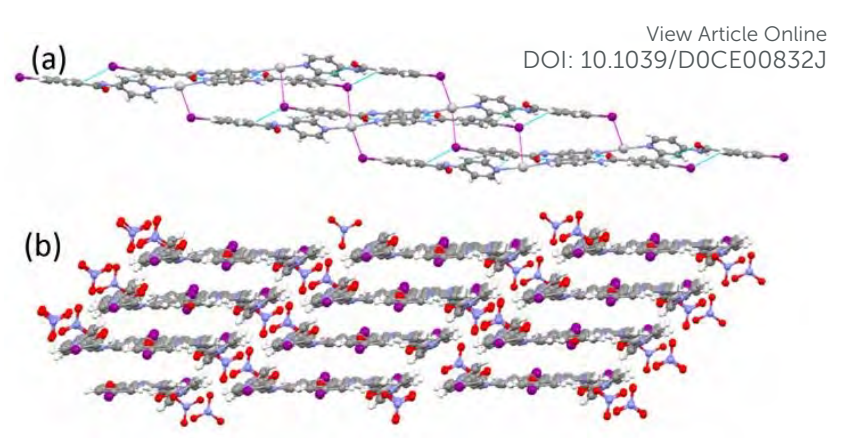

Figure 5. A view showing $\mathrm{C}-1 \cdots \mathrm{Ag}$ interactions in violet (a) and nitrate anion linking planes by $\mathrm{C}-1 \cdots \mathrm{O}$ halogen bonding and $\mathrm{Ag} \cdots \mathrm{O}$ interactions $(\mathrm{b})$ in $\mathbf{1}$.

Zinc complexes $\left[\mathrm{ZnBr}_{2}(\mathrm{INPBA})_{2}\right](2)$ and $\left[\mathrm{Zn}(\mathrm{OCOPh})_{2}(\text { INPBA })_{2}\right](3)$. The zinc(II) complexes $\mathbf{2}$ and $\mathbf{3}$ crystallize in the monoclinic $P 2_{1} / c$ and orthorhombic $P b c n$ space groups, respectively. The asymmetric units of $\mathbf{2}$ consist of a $\mathrm{Zn}^{2+}$ ion, two bromides and two INPBA ligands, while that of $\mathbf{3}$ consists of half a $\mathrm{Zn}^{2+}$ ion, on a two-fold rotation axis, one benzoate anion and one INPBA ligand. In both structures the metal ion has a distorted tetrahedral geometry with $\mathrm{ZnBr}_{2} \mathrm{~N}_{2}$ in $\mathbf{2}$ and $\mathrm{ZnN}_{2} \mathrm{O}_{2}$ in 3. As shown in Figure 6, different conformations of INPBA (Table 2) mean that the iodine-to-iodine distances in $\mathbf{2}$ and $\mathbf{3}$ (Figure 6) are 19.3 and $23.3 \AA$, respectively. In addition, the two INPBA ligands coordinated to a metal atom exhibit a trans conformation with respect to the orientation of the carbonyl groups, i.e., both carbonyl groups are located in opposite side (Figure 6).

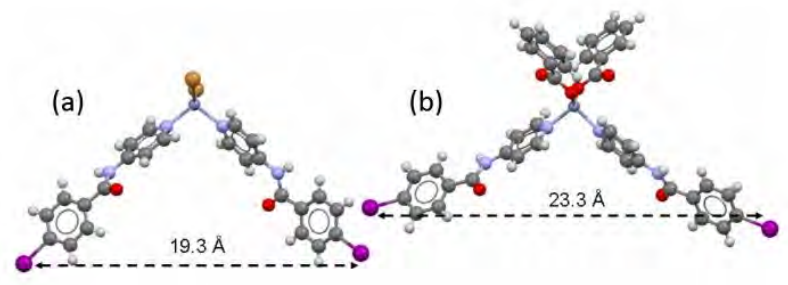

Figure 6. Coordination environment of zinc(II) in $\mathbf{2}$ (a) and $\mathbf{3}$ (b).

The supramolecular arrangement of $\mathbf{2}$ is formed due to $\mathrm{C}-|\cdots|$ halogen bonding interactions and hydrogen bonds formed by each of the two amide groups. A summary of the data for the halogen and hydrogen bonding interactions is provided in Table 3 and Table S1 (ESI), respectively. Each iodine atom of $\mathbf{2}$ has a different role; I(2) is a halogen bond donor while I(1) atom acts as a halogen bond acceptor $\left(C-|(2) \cdots|(1) 3.938 \AA\right.$, $\left.166.2^{\circ}\right)$. The $I(2)$ iodine atom is oriented towards the equatorial belt of $I(1)$ iodine atom, thus forming an angle close to $90^{\circ}\left(I_{\text {donor }} \cdots I_{\text {aceptor }}-C\right.$ $\left.75.1^{\circ}\right)$, which promotes the formation of a helical chain that propagates along a $2_{1}$ screw axis in the $b$-direction. The length of the repeating unit of the helical chain is $27.8 \AA$ and the distance between contiguous zinc cations is $24.2 \AA$, as shown in Figure $7 a$ and $b$. Each of these chains is linked to two enantiomeric helix (Figure 7c) through hydrogen bonds between the amide group along the $c$-axis $(\mathrm{N}(4)-\mathrm{H} \cdots \mathrm{O}(2) 2.795$ $\AA$, $\left.149.2^{\circ}\right)$ of the INPBA ligand with the more tilted conformation with respect to carboxamide group $\left(\Phi_{1}=-18.4^{\circ}\right.$; $\Phi_{3}=-26.8^{\circ}$ ) (Table 2). 
(a)
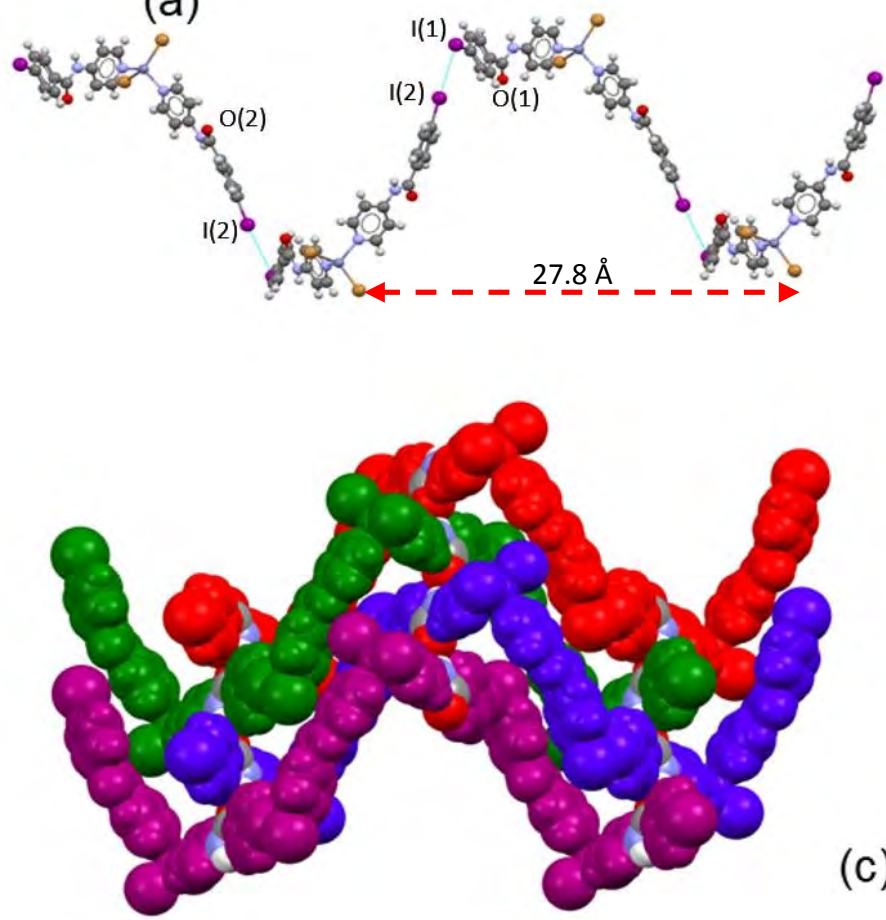

(c)
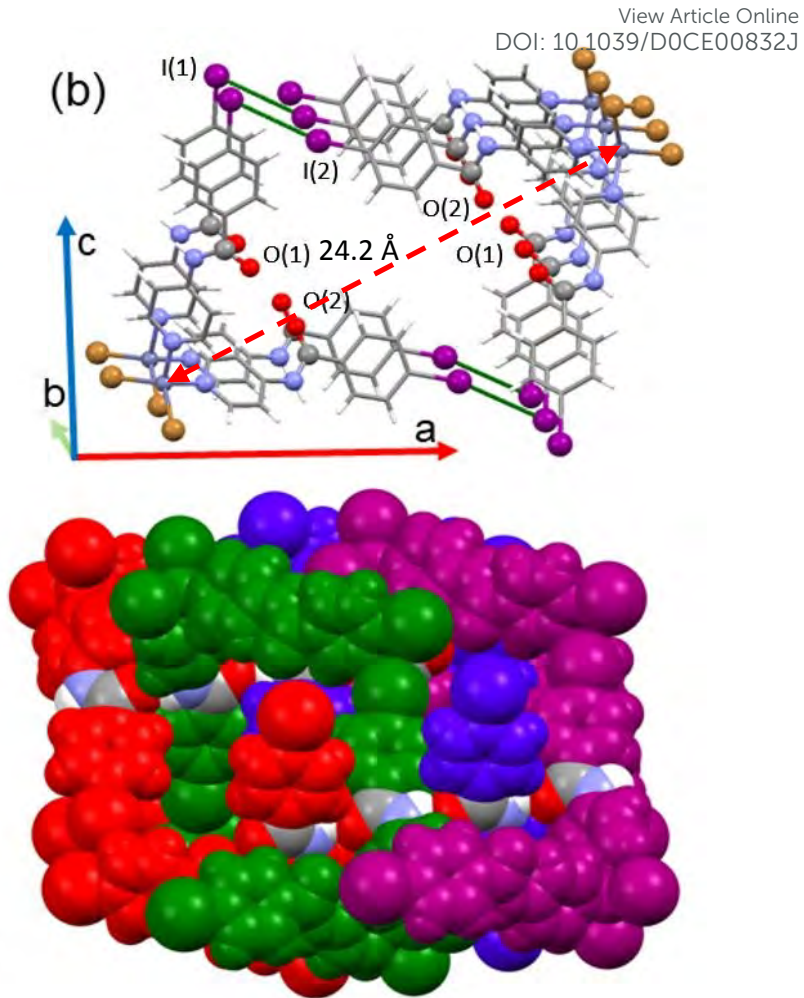

Figure 7. (a) A view along the $b$-axis of a helical strand of $\mathbf{2}$ formed by $|\cdots|$ halogen bonding; (b) view along the $c$-axis, and (c) enantiomeric helical strand hydrogen bonded along the $b$ - and $c$-axes.

The second amide group forms hydrogen bonds with one of the bromine atoms $\left(\mathrm{N}(2)-\mathrm{H} \cdots \operatorname{Br}(1) 3.743 \AA, 150.9^{\circ}\right)^{42}$ and this leads to a ladder arrangement due to the formation of weak hydrogen bonds $\left(C(5)-H \cdots O(1)=C, 3.577 \AA, 158.1^{\circ}\right.$ ) (Figure $S 5$ in the ESI). Evidence for the different environments of the carbonyl groups is provided by two bands at 1695 and $1670 \mathrm{~cm}^{-1}$ in the ATR-IR spectra.

The supramolecular organization of $\mathbf{3}$ is determined by the halogen bonding between the iodine atom and carbonyl oxygen atom of the carboxamide group $(C-I(1) \cdots O(1)=C, 3.257 \AA$, $\left.148.8^{\circ}\right)$ and hydrogen bond $\mathrm{N}(1)-\mathrm{H} \cdots \mathrm{O}(3)=\mathrm{C}\left(2.822 \AA, 167^{\circ}\right)$ in which the hydrogen bond acceptor is the carbonyl oxygen of the ester group. Halogen bonding provides corrugated layers that extend along the $a c$ plane while hydrogen bonding connects these planes along the $b$-axis to give a three-dimensional arrangement (Figure 8).

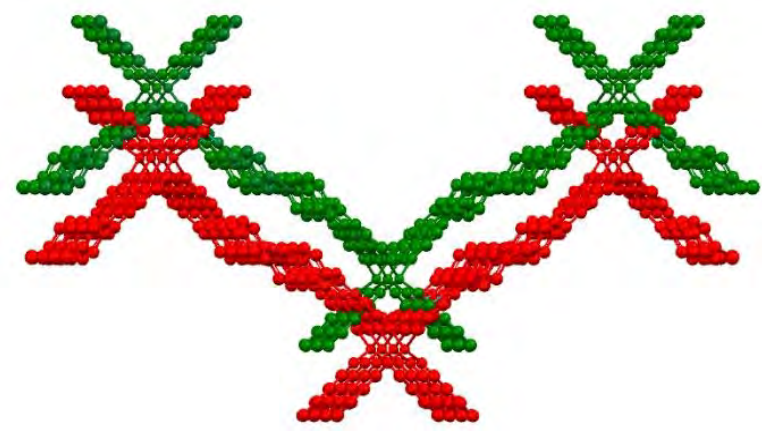

Figure 8. Corrugated layers stacking along the $b$-axis in $\mathbf{3}$.
Mercury extended coordination polymer $\left[\mathrm{HgI}_{2} \text { (INPBA) }\right]_{n}$ (4). $X$-ray crystallography revealed that 4 crystallizes in the $P 2_{1} / c$ monoclinic space group. The asymmetric unit contains one $\mathrm{Hg}^{2+}$ ion, two iodide anions and one INPBA ligand. The mercury(II) cation has a rhomboidal-based pyramid coordination sphere, with four iodide ligands in the base plane and the substituted pyridine nitrogen atom at the axial position (Figure 9).

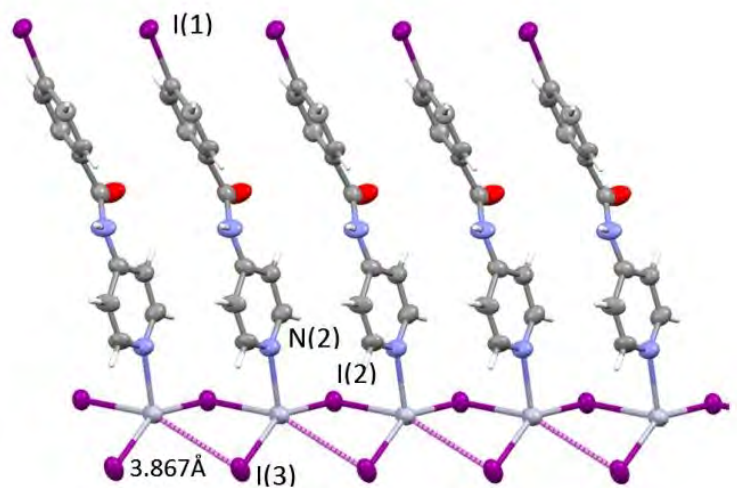

Figure 9. A view showing the rhomboidal base pyramid coordination sphere of mercury(II) in $\mathbf{4}$. Thermal ellipsoids are drawn at the $50 \%$ probability level.

The rhomboidal base has two short $\mathrm{Hg}-\mathrm{I}$ bonds (2.651 and $2.666 \AA$ ) and two long ones ( 3.238 and $3.867 \AA$ ). The very long $\mathrm{Hg}-\mathrm{I}$ interatomic distance $(3,867 \AA$ ) (violet dashed lines in Figure 9 ) is too long to be considered a bond (values for the van der Waals radii range from $1.82^{43}$ to $2.24 \AA^{44,45}$ for mercury and 2.1 
$\AA$ for iodine), but short enough to point it out. The mercury coordination geometry can also been described as a see-saw structure with a geometrical index $\tau_{4}^{46,47}$ of 0.74 and dihedral angle between the $\mathrm{I}-\mathrm{Hg}-\mathrm{I}$ and $\mathrm{I}-\mathrm{Hg}-\mathrm{N}$ planes of $89.7^{\circ}$.

Mercury rhomboid-pyramidal coordination units share edges of their base and all INPBA ligands point to the same side of the polymer chain along the $c$-axis, as shown in Figure 9. This organization promotes $\pi-\pi$ stacking, since the adjacent molecules of INPBA are related by a translation along the $a$-direction and the distance between planes containing pyridyl moieties is $3.559 \AA$ and $3.587 \AA$ between the planes containing phenyl rings. In addition, $1 \mathrm{D}$ chains are linked by halogen bonding $C(1)-I(1) \cdots \mid(3)\left(3.86 \AA\right.$ and $\left.175^{\circ}\right)$. This $X B$ in green in Figure 10 , gives rise to corrugated planes that are connected by weak hydrogen bonds involving the oxygen of the carbonyl group $\left(\mathrm{C}(5)-\mathrm{H} \cdots \mathrm{O}(1)=\mathrm{C}(7) 2.616 \AA\right.$, $\left.168.9^{\circ}\right)$, metal iodide $\left(\mathrm{N}(1)-\mathrm{H} \cdots \mid(3)-\mathrm{Hg}(1) 3.340 \AA, 157.9^{\circ}\right)$ and the carbon-bound iodine atom of the INPBA ligand $(C(2)-H \cdots \mid(1)-C(1) 3.314 \AA$, $\left.140.6^{\circ}\right)$. This gives rise to a three-dimensional organization, as shown in Figure 10.

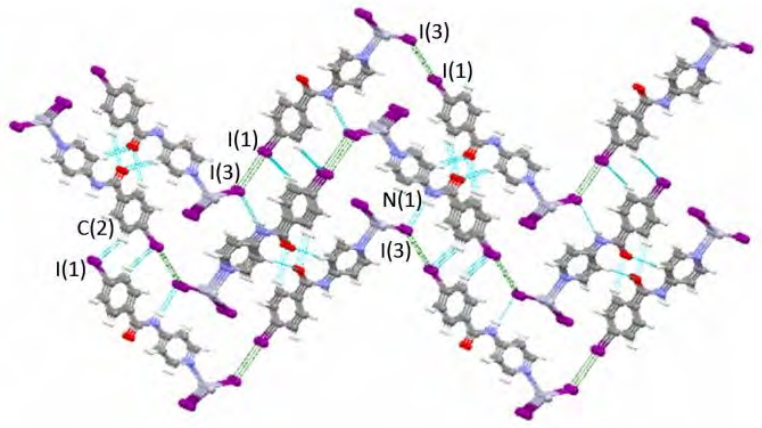

Figure 10. Three dimensional organization in the crystal structure of 4. Corrugated planes formed by halogen bonding, in green, connected by hydrogen bonds, in blue.

Comparison of the structure of $\mathbf{4}$ with others in which the mercury atom has a similar coordination ${ }^{47-52}$ shows that the establishment of halogen bonding causes an elongation of the $\mathrm{Hg}-\mathrm{I}$ bond, shortening of the $\mathrm{Hg}-\mathrm{N}$ bond and a deviation of the mercury atom from the plane defined by the iodine atoms. Thus, the structure of $\mathbf{4}$ has the longest $\mathrm{Hg}-$ I distance (2.651 $\AA$ ), the shortest $\mathrm{Hg}-\mathrm{N}$ bond distance $(2.368 \AA$ ) and the longest distance between the mercury atom and the plane defined by the iodine atoms $(0.66 \AA)$. These effects are consistent with halogen bonding wherein the iodine atom attached to the phenyl moiety behaves as an halogen bond donor and the iodine atom attached to mercury as an halogen bond acceptor.

\section{Hirshfeld surface analysis}

The intermolecular contacts in the crystal structures of INPBA and 1 to $\mathbf{4}$ were analysed by considering the Hirshfeld surface using the CrystalExplorer programme. ${ }^{53}$ Hirshfeld surfaces can encode different properties in a three-dimensional picture and all of this information can be summarized in a bidimensional fingerprint $\left(d_{i}, d_{e}\right)$ graph. ${ }^{54}$ As expected, the Hirshfeld surfaces of each crystallographically independent INPBA ligand in the crystal structures of INPBA and $\mathbf{1}$ to $\mathbf{4}$ revealed the close contacts of halogen and hydrogen bonding, in addition, together

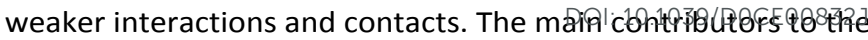
Hirshfeld surface are weak dispersion forces such as $\mathrm{H} \cdots \mathrm{H}, \mathrm{C} \cdots \mathrm{H}$, and $\mathrm{I} \cdots \mathrm{H}$. The fingerprint plots (Figure 11) of each INPBA ligand are different, including those belonging to the same crystal structure, and they are characterized by spikes that correspond to $\mathrm{O} \cdots \mathrm{H}, \mathrm{C} \cdots \mathrm{H}$ and $\mathrm{l} \cdots \mathrm{H}$ interactions denoted as $\mathrm{a}, \mathrm{b}$ and $\mathrm{c}$, respectively. The major differences between the graphs are the presence or absence of a clear area near to the centre of the plot, i.e., in the vicinity of $\left(d_{i}, d_{e}\right) \approx 1.8-2.0 \AA$ (named $d$ ). These are related to the planar $\pi-\pi$ stacking (C...C and $\mathrm{C} \cdots \mathrm{N}$ interactions).

The $\pi-\pi$ stacking contribution to the Hirshfeld surfaces for INPBA and 1 to 4 structures ranged from 0 to almost 14\% in INPBA and 1, respectively. However, in the silver complex the ligand with the more planar conformation has a greater $\pi-\pi$ interaction but there is no correlation between the conformation and $\pi-\pi$ stacking in the studied structures.
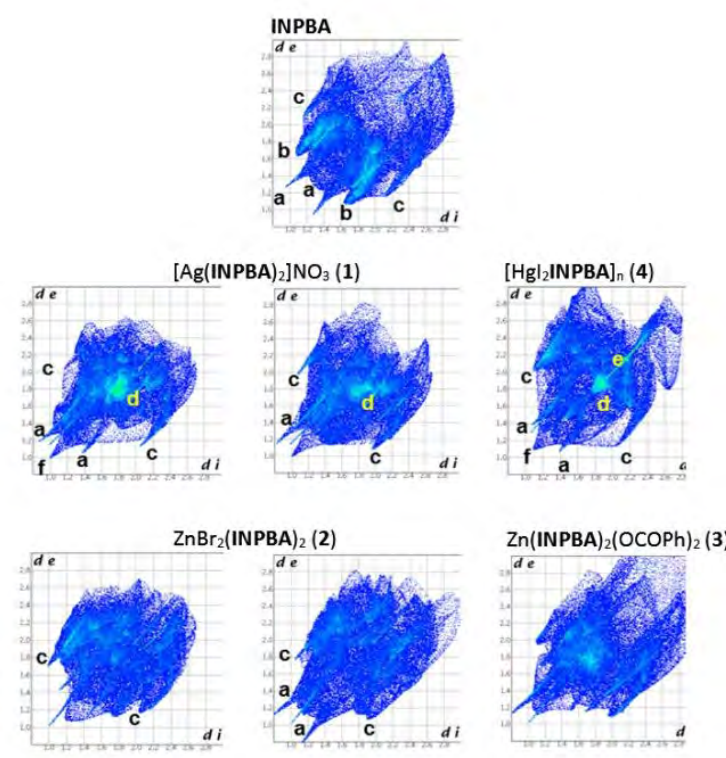

Figure 11. Fingerprint plots of the INPBA ligand, crystallographically different, in crystal structures of INPBA and 1 to 4

\section{Conclusions}

The preparation and crystal structures of 4-iodo-N-(4-pyridyl)benzamide (INPBA), three metal complexes, $\left.\quad\left[\mathrm{Ag}(\mathrm{INPBA})_{2}\right] \mathrm{NO}_{3}, \quad\left[\mathrm{ZnBr}_{2} \text { (INPBA) }\right)_{2}\right]$ [Zn(OCOPh $\left.)_{2}(\text { INPBA })_{2}\right]$, and a coordination extended coordination polymer $\left[\mathrm{Hgl}_{\mathbf{2}} \text { (INPBA) }\right]_{n}$ are reported. The INPBA ligand has been proved to be very versatile and give rise to different types of interactions such as coordination with metals, $\pi-\pi$ stacking, halogen bonding and hydrogen bonding. This ability of the INPBA promotes an increase in dimensionality and improves the stability of 1-4 structures. Halogen bonding of the type $\mathrm{C}-\left|\cdots \mathrm{A}^{-}\left(\mathrm{A}^{-}=\mathrm{NO}_{3}^{-}\right), \mathrm{C}-\right| \cdots \mathrm{O}=\mathrm{C}$ and $\mathrm{C}-|\cdots|-\mathrm{Hg}$, gives rise to planes in compounds $\mathbf{1}, \mathbf{3}$ and $\mathbf{4}$, respectively. Helical chains with a repeat unit length of $27.76 \AA$ are formed in $\mathbf{2}$ by $\mathrm{C}-1 \cdots \mid-C$ halogen bonding. Furthermore, the simultaneous action of 
these interactions highlights the complexity and challenge in programming the supramolecular assembly of metal organic networks, since small variations can cause very significant structural changes.

\section{Experimental}

4-lodobenzoyl chloride, 4-aminopyridine, triethylamine, silver nitrate, zinc bromide and mercury(II) iodide were used as received from commercial sources (Sigma-Aldrich or Acros). ${ }^{1} \mathrm{H}-\mathrm{NMR}$ and ${ }^{13} \mathrm{C}-\mathrm{NMR}$ spectra were recorded on a Bruker Avance 300 spectrometer. Infrared (IR) spectra were recorded on an ATR unit-upgraded (Golden Gate) Bruker FT-IR Vertex 70 spectrophotometer. Mass spectra were recorded on a VG Auto-spec system with the ESI technique. $\mathrm{C}, \mathrm{H}$, and $\mathrm{N}$ analyses were carried out on a Perkin-Elmer 2400 microanlyzer.

\section{Synthesis of 4-iodo-N-(4-pyridyl)benzamide (INPBA)}

A solution of 4-iodobenzoyl chloride $(1.32 \mathrm{~g}, 5.0 \mathrm{mmol})$ and triethylamine $(0.50 \mathrm{~g}, 5.0 \mathrm{mmol})$ in $50 \mathrm{~mL}$ of chloroform was cooled to $0{ }^{\circ} \mathrm{C}$ in an ice bath for $10 \mathrm{~min}$. 4-Aminopyridine $(0.470$ $\mathrm{g}, 5.0 \mathrm{mmol}$ ) was added slowly to the cold solution over a period of $10 \mathrm{~min}$. The reaction mixture was stirred at room temperature for $16 \mathrm{~h}$ and concentration afforded a white precipitate. The solid was filtered off and washed several times with cold chloroform. Yield $1.33 \mathrm{~g}(82 \%) .{ }^{1} \mathrm{H}-\mathrm{NMR}$ spectrum $\left(d_{6}\right.$-DMSO, $\left.300 \mathrm{MHz}\right) \delta$ from TMS: $7.63(\mathrm{~m}, 3 \mathrm{H}, \mathrm{Bz}), 7.78(\mathrm{~d}, 2 \mathrm{H}$, Py), 7.95 (d, 2H, o-Bz), 8.47 (d, 2H, Py), 10.60 (s, NH). ${ }^{13} \mathrm{C}-\mathrm{NMR}$ spectrum $\left(d_{6}\right.$-DMSO, $\left.62.5 \mathrm{MHz}\right): 114.70,128.56,129.15$, 132.76, 134.96, 146.66, 150.97, 167.19. IR (ATR) $v_{\max }$ (neat) / $\mathrm{cm}^{-1}$ : 3332, 1660, 1587, 1502, 1477, 1413, 1330, 1282, 1210, 822, 748. High resolution positive ESI-MS (a.m.u.): Calcd. for $M$ $+\mathrm{H}$ : 324.9834; Found: 324.9827. Anal. Calcd. for $\mathrm{C}_{12} \mathrm{H}_{9} \mathrm{IN}_{2} \mathrm{O}$ : C 44.47, H 2.80, N 8.64; Found: C 44.22, H 2.67, N 8.61.

\section{Preparation of INPBA metal complexes 1, 2 and 4}

A solution of INPBA $(32 \mathrm{mg}, 0.10 \mathrm{mmol})$ in THF $(10 \mathrm{~mL})$ was added to a solution of inorganic salt $(0.1 \mathrm{mmol})$ in methanol (5 $\mathrm{mL}$ ). The solution was allowed to slowly evaporate with orbital stirring over a period of $48 \mathrm{~h}$, during which it generated colourless crystals.

[Ag(INPBA) $\left.)_{2}\right]_{N_{3}}(\mathbf{1})$ Obtained $36.0 \mathrm{mg}$, yield 73\%. IR (ATR) $v_{\max }$ (neat) $/ \mathrm{cm}^{-1}: 3342,1680,1591,1509,1478,1425,1378,1323$, 1288, 1209, 1091. High resolution positive ESI-MS (a.m.u.): Calcd. for $\mathrm{Ag}(\mathrm{INPBA})_{2}$ : 754.8570; Found: 754.8599. Anal. Calcd. for $\mathrm{C}_{24} \mathrm{H}_{18} \mathrm{I}_{2} \mathrm{~N}_{5} \mathrm{O}_{5} \mathrm{Ag}$ : $\mathrm{C} 35.23, \mathrm{H} 2.22, \mathrm{~N}$ 8.56; Found: $\mathrm{C} 34.89, \mathrm{H}$ 2.14, N 8.54.

[ $\mathrm{ZnBr}_{2}$ (INPBA) $)_{2}$ (2) Obtained $39.1 \mathrm{mg}$, yield 71\%. IR (ATR) $v_{\max }$ (neat) $/ \mathrm{cm}^{-1}$ : 3349, 1695, 1670, 1613, 1585, 1510, 1497, 1478, 1427, 1332, 1294, 1262, 1207, 1092. High resolution positive ESI-MS (a.m.u.): Calcd. for $\left[\mathrm{ZnBr}_{2}(\mathrm{INPBA})_{2}\right]+\mathrm{Na}$ : 894.7055; Found: 894.7036. Anal. Calcd. for $\mathrm{C}_{24} \mathrm{H}_{18} \mathrm{Br}_{2} \mathrm{I}_{2} \mathrm{~N}_{4} \mathrm{O}_{2} \mathrm{Zn}$ : C 33.00, $\mathrm{H}$ 2.08, N 6.41; Found: C 32.52, H 2.01, N 6.25.

[Hgl ${ }_{2}(\text { INPBA) }]_{\mathrm{n}}(4)$ Obtained $63.1 \mathrm{mg}$, yield $81 \%$. IR (ATR) $v_{\max }$ (neat) $/ \mathrm{cm}^{-1}: 3368,1702,1603,1585,1578,1497,1475,1419$, 1327, 1264, 1208, 1091. Anal. Calcd. for $\mathrm{C}_{12} \mathrm{H}_{9} \mathrm{I}_{3} \mathrm{~N}_{2} \mathrm{OHg}$ : C 18.51, H 1.17, N 3.60; Found: C 18.97, H 1.07, N 3.58

\section{Preparation of $\left[\mathrm{Zn}(\mathrm{OCOPh})_{2}(\text { INPBA })_{2}\right](3)$}

View Article Online X-ray quality single crystals of $\mathbf{3}$ were obtained by three-layer diffusion, INPBA in methanol, sodium benzoate in ethanol and zinc nitrate in water.

\section{X-ray crystallographic analysis}

X-ray diffraction experiments were carried out on Oxford-diffraction Xcalibur $S$ and Bruker AXS D8 Venture diffractometers. Mo-K $\alpha$ radiation was used for data collection for INPBA, 1, 3 and $\mathbf{4}$ and $\mathrm{Cu}-\mathrm{K} \alpha$ for 2. XSCANS and CrysAlis software packages were used to process data. Final cell parameters were obtained by global refinement of reflections obtained by integration of all the frames data. The structures were solved by direct methods and refined by the full-matrix method based on $F^{2}$ using the SHELXTL programme. The non-hydrogen atoms of INPBA and $\mathbf{1}$ to $\mathbf{4}$ were refined anisotropically, the hydrogen atoms of 1, 3, 4 were observed in difference electron density maps and refined isotropically. Hydrogen atoms of INPBA and $\mathbf{2}$ were included at idealized positions by using a riding model and refined isotropically. The crystal parameters and basic information relating data collection and structure refinement are summarized in Table 1.

\section{Hirshfeld surface analysis}

Hirshfeld surfaces and the associated fingerprint plots were calculated using CrystalExplorer, ${ }^{53}$ which accepts a structure input file in the CIF format. Bond lengths to hydrogen atoms were set to typical neutron values $(\mathrm{C}-\mathrm{H}=1.083 \AA, \mathrm{N}-\mathrm{H}=1.009$ $\AA$, $\mathrm{O}-\mathrm{H}=0.983 \AA$ ) . The distance from the Hirshfeld surface to the nearest atoms outside and inside the surface are characterized by the quantities $d_{e}$ and $d_{i}$, respectively, and the normalized contact distance based on these, $d_{\text {norm }}=\left(d_{i}-r_{i}^{\mathrm{vdW}}\right) /$ $\left.r_{i}^{\mathrm{vdW}}+\left(d_{e}-r_{e}^{\mathrm{vdW}}\right) / r_{e}^{\mathrm{vdW}}\right)$, with $r_{i}^{\mathrm{vdW}}$ and $r_{e}^{\mathrm{vdW}}$ being the van der Waals radii of the atoms. The $2 \mathrm{D}$ histograms, fingerprints, plot distance external to the surface $\left(d_{e}\right)$ versus distance internal to the surface $\left(d_{i}\right)$ : is the distance from the surface to the nearest atom in the molecule itself.

\section{Computational methods}

Quantum chemical calculations were performed using the Gaussian 09 package. ${ }^{55}$ Optimization of dimers extracted from experimental crystal structures (see Figure 54 ) were carried out using DFT in conjunction with the B3LYP exchange-correlation functional, ${ }^{56-58}$ and Grimme D3BJ van der Waals dispersion correction. ${ }^{59}$ The $6-311 \mathrm{G}^{++}(d, p)$ basis $\operatorname{set}^{60}$ was used for all atoms except the iodine atom, for which the DGDZVP one was employed..$^{61}$ The optimization was conducted without geometry restrictions. Vibrational frequency analysis was used to characterize the stationary points as minima, by checking that they did not present any imaginary frequency. The interaction energies between the different monomers that form part of the complexes were calculated at the same level of theory as the difference between the total complex energy and the sum of the total energies of the monomers. The interaction energies $(\Delta E)$ were corrected $\left(\triangle E_{B S S E}\right)$ using the counterpoise method of Boys-Bernardi so as to eliminate the basis set superposition error (BSSE). ${ }^{62}$ Moreover, the interaction energies of the 
optimized complexes were corrected for scaled $(0.9887)^{63}$ zero-point energy differences (obtained from the frequency calculations described above).

\section{Acknowledgements}

Thanks are given to the Crystallography Service of the University of Zaragoza-CSIC (Spain), University of Pais Vasco (Spain) and National University of Singapore and Servicio General de Apoyo a la Investigación SAI, Universidad de Zaragoza. This work was supported by the Ministerio de Economía, Industria y Competitividad under the projects PGC2018-093761-B-C31, PGC2018-097583-B-100 and MAT2017-84838-P. Authors acknowledge support from Gobierno de Aragón-FEDER for funding Crystal and Polymers Group (E47_20R, FEDER 2014-2020 Construyendo Europa desde Aragón).

\section{Notes and references} E. R. T. Tiekink and J. J. Vittal, Frontiers in crystal engineering, Wiley, 2006.

2 M. D. Allendorf, C. A. Bauer, R. K. Bhakta and R. J. T. Houk, Chem. Soc. Rev., 2009, 38, 1330-1352.

3 P. A. Gale and J. W. Steed, Supramolecular chemistry : from molecules to nanomaterials, Wiley, 2012. A. Mukherjee, S. Tothadi and G. R. Desiraju, Acc. Chem. Res., 2014, 47, 2514-2524. B. Moulton and M. J. Zaworotko, Chem. Rev., 2001, 101, 1629-1658.

M. C. Etter, Acc. Chem. Res., 1990, 23, 120-126.

L. Brammer, Chem. Soc. Rev., 2004, 33, 476-489.

K. S. Kim, P. Tarakeshwar and J. Y. Lee, Chem. Rev., 2000, 100, 4145-4185.

R. Bertani, P. Sgarbossa, A. Venzo, F. Lelj, M. Amati, G. Resnati, T. Pilati, P. Metrangolo and G. Terraneo, Coord. Chem. Rev., 2010, 254, 677-695.

L. Brammer, G. Mínguez Espallargas and S. Libri, CrystEngComm, 2008, 10, 1712--1727.

M. Borovina, I. Kodrin and M. Đaković, CrystEngComm 2018, 20, 539-549.

B. Li, S. Q. Zang, L. Y. Wang and T. C. W. Mak, Coord. Chem. Rev., 2016, 308, 1-21.

Y. V. Torubaev, I. V. Skabitskiy, P. Rusina, A. A. Pasynskii, D. K. Rai and A. Singh, CrystEngComm, 2018, 20, 2258-2266.

A. S. Mahadevi and G. N. Sastry, Chem. Rev., 2016, 116 2775-2825.

C.-Y. Lin, Z.-K. Chan, C.-W. Yeh, C.-J. Wu, J.-D. Chen and J.C. Wang, CrystEngComm, 2006, 8, 841-846.

S. K. Chandran, R. Thakuria and A. Nangia, CrystEngComm, 2008, 10, 1891-1898.

H. R. Khavasi and A. A. Tahrani, CrystEngComm, 2013, 15 5799-5812.

H. R. Khavasi and A. Azhdari Tehrani, Inorg. Chem., 2013, 52, 2891-2905.

C. J. Wu, C. Y. Lin, P. C. Cheng, C. W. Yeh, J. Der Chen and J.

C. Wang, Polyhedron, 2011, 30, 2260-2267.

J. Gamekkanda, A. Sinha, J. Desper, M. Đaković and C.

Aakeröy, Crystals, 2017, 7, 226.

View Article Online

21

22

23

24

25

26

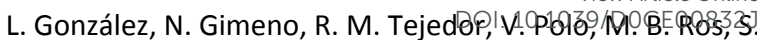
Uriel and J. L. Serrano, Chem. Mater., 2013, 25, 4503-4510. L. González, R. M. Tejedor, E. Royo, B. Gaspar, J. Munárriz, A. Chanthapally, J. L. Serrano, J. J. Vittal and S. Uriel, Cryst. Growth Des., 2017, 17, 6212-6223.

K. Raatikainen and K. Rissanen, Chem. Sci., 2012, 3, 12351239.

P. Politzer, J. S. Murray and T. Clark, Phys. Chem. Chem. Phys., 2010, 12, 7748-7757.

H. R. Khavasi, M. Hosseini, A. A. Tehrani and S. Naderi, CrystEngComm, 2014, 16, 4546-4553.

S. Saha and G. R. Desiraju, J. Am. Chem. Soc., 2017, 139, 1975-1983.

P. Politzer, P. Lane, M. C. Concha, Y. Ma and J. S. Murray, J. Mol. Model., 2007, 13, 305-311.

G. Cavallo, P. Metrangolo, R. Milani, T. Pilati, A. Priimagi, G. Resnati and G. Terraneo, Chem. Rev., 2016, 116, 24782601.

C. B. Aakeröy, N. Schultheiss, J. Desper and C. Moore, CrystEngComm, 2007, 9, 421-426.

L. C. Gilday, S. W. Robinson, T. A. Barendt, M. J. Langton, B. R. Mullaney and P. D. Beer, Chem. Rev., 2015, 115, 71187195.

A. Farina, S. V. Meille, M. T. Messina, P. Metrangolo, G. Resnati and G. Vecchio, Angew. Chem. Int. Ed., 1999, 38, 2433-2436.

J. Cao, X. Yan, W. He, X. Li, Z. Li, Y. Mo, M. Liu and Y.-B. Jiang, J. Am. Chem. Soc., 2017, 139, 6605-6610.

T. A. Logothetis, F. Meyer, P. Metrangolo, T. Pilati and G. Resnati, New J. Chem., 2004, 28, 760- 763.

V. R. Hathwar, R. G. Gonnade, P. Munshi, M. M.

Bhadbhade and T. N. G. Row, Cryst. Growth Des., 2011, 11, 1855-1862.

J. Lieffrig, A. G. Niassy, O. Jeannin and M. Fourmigué, CrystEngComm, 2015, 17, 50-57.

C. J. Massena, N. B. Wageling, D. A. Decato, E. Martin Rodriguez, A. M. Rose and O. B. Berryman, Angew. Chem. Int. Ed., 2016, 55, 12398-12402.

L. González, S. Graus, R. M. Tejedor, P. López, J. Elguero, J. L. Serrano and S. Uriel, CrystEngComm, 2018, 20, 31673170.

J. C. Noveron, M. S. Lah, R. E. Del Sesto, A. M. Arif, J. S. Miller and P. J. Stang, J. Am. Chem. Soc., 2002, 124, 66136625.

K. Donnelly, J. F. Gallagher, A. J. Lough and IUCr, Acta Crystallogr. Sect. C Cryst. Struct. Commun., 2008, 64, 0335o340.

L. González, S. Graus, R. M. R. M. Tejedor, P. López, J. Elguero, J. L. J. L. Serrano and S. Uriel, CrystEngComm, 2018, 20, 3167-3170.

H. R. Khavasi and M. Esmaeili, CrystEngComm, 2014, 16, 8479-8485.

K. Biradha, C.-Y. Su and J. J. Vittal, Cryst. Growth Des, 2011, 11, 875-886.

H. J. Bohórquez and R. J. Boyd, Chem. Phys. Lett., 2009, 480, 127-131. 

832-834.

45 S.-Z. Hu, Z.-H. Zhou and B. E. Robertson, Z. Kryst., 2009, 224, 375-383.

46 L. Yang, D. R. Powell and R. P. Houser, Dalt. Trans., 2007, 955-964.

47 A. A. Tehrani, A. Morsali and M. Kubicki, Dalt. Trans., 2015, 44, 5703-5712.

48 Y.-H. Shen, J.-G. Liu and D.-J. Xu, Acta Crystallogr., 2005, E61, m1880-m1882.

49 W. T. Chen, M. S. Wang, X. Liu, G. C. Guo and J. S. Huang, Cryst. Growth Des., 2006, 6, 2289-2300. C. Hu, I. Kalf and U. Englert, CrystEngComm, 2007, 9, 603610.

51 Q.-Y. Du, J.-H. Qin and H.-X. Wu, Chin. J. Struct. Chem., 2007, 26, 817-821.

52 H. P. Zhou, J. H. Yin, L. X. Zheng, P. Wang, F. Y. Hao, W. Q. Geng, X. P. Gan, G. Y. Xu, J. Y. Wu, Y. P. Tian, X. T. Tao, M. H. Jiang and Y. H. Kan, Cryst. Growth Des., 2009, 9, 37893798.

53 S.K. Wolff, D. J. Grimwood, J. J. McKinnon, M. J. Turner, D. Jayatilaka and M. A. Spackman, CrystalExplorer (Version 3.1) Univ. West. Aust. 2012.

54 M. A. Spackman and D. Jayatilaka, CrystEngComm, 2009, 11, 19-32.

55 M. J. Frisch, G. W. Trucks, H. B. Schlegel, G. E. Scuseria, M. A. Robb, J. R. Cheeseman, G. Scalmani, V. Barone, B. Mennucci, G. A. Petersson, H. Nakatsuji, M. Caricato, X. Li, H. P. Hratchian, A. F. Izmaylov, J. Bloino, G. Zheng, J. L. Sonnenberg, M. Hada, M. Ehara, K. Toyota, R. Fukuda, J. Hasegawa, M. Ishida, T. Nakajima, Y. Honda, O. Kitao, H. Nakai, T. Vreven, J. Montgomery, J. A., J. E. Peralta, F. Ogliaro, M. Bearpark, J. J. Heyd, E. Brothers, K. N. Kudin, V. N. Staroverov, R. Kobayashi, J. Normand, K. Raghavachari, A. Rendell, J. C. Burant, S. S. Iyengar, J. Tomasi, M. Cossi, N. Rega, J. M. Millam, M. Klene, J. E. Knox, J. B. Cross, V. Bakken, C. Adamo, J. Jaramillo, R. Gomperts, R. E. Stratmann, O. Yazyev, A. J. Austin, R. Cammi, C. Pomelli, J. W. Ochterski, R. L. Martin, K. Morokuma, V. G. Zakrzewski, G. A. Voth, P. Salvador, J. J. Dannenberg, S. Dapprich, A. D. Daniels, O. . Farkas, J. B. Foresman, J. V. Ortiz, J. Cioslowski and D. J. Fox, Gaussian 09, Gaussian Inc., Wallinford, CT, 2016. C. T. Lee, W. T. Yang and R. G. Parr, Phys. Rev. B, 1988, 37, 785-789.

57 A. D. Becke, J. Chem. Phys., 1993, 98, 5648-5652.

58 A. D. Becke, J. Chem. Phys., 1993, 98, 1372-1377.

59 S. Grimme, S. Ehrlich and L. Goerigk, J. Comput. Chem., 2011, 32, 1456-1465.

60 R. Krishnan, J. S. Binkley, R. Seeger and J. A. Pople, J. Chem. Phys., 1980, 72, 650-654.

61 N. Godbout, D. R. Salahub, J. Andzelm and E. Wimmer, Can. J. Chem., 1992, 70, 560-571.

62 S. F. Boys and F. Bernardi, Mol. Phys., 1970, 19, 553-566.

63 J. P. Merrick, D. Moran and L. Radom, J. Phys. Chem. A, 2007, 111, 11683-11700. 